Hussain A Obaidi BDS, MSc (Prof)

Sarmad S Al-Qassar BDS, MSc (Asst Lec)

\section{Elasticity and Plasticity Behaviors of the Orthodontic Arch Wires}

\author{
Dept of Pedod, Orthod and Prev Dentistry \\ College of Dentistry, University of Mosul
}

$$
\begin{aligned}
& \text { الحخلاصة }
\end{aligned}
$$

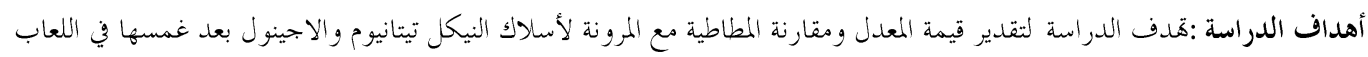

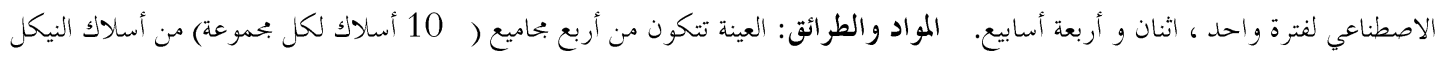

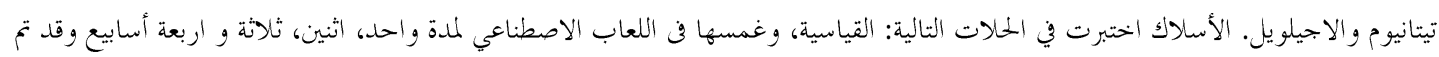

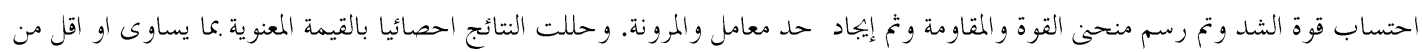

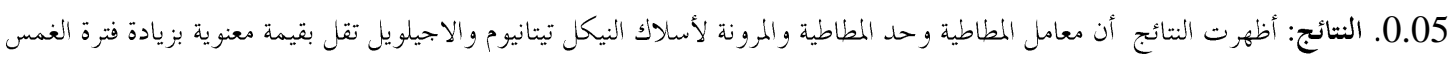

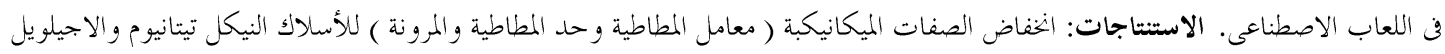

$$
\begin{aligned}
& \text { بزيادة فترة الغمس في اللعاب الاصطناعي لا تشجع استخدامها سريريا لفترة طويلة. }
\end{aligned}
$$

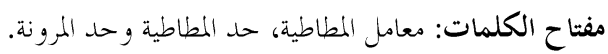

\begin{abstract}
Aims: To evaluate the mean value and compare the: elasticity and plasticity of the Nickel Titanium and Elgilloy arch wires after emersion in artificial saliva for one, two and four weeks. Materials and Methods: The sample consisted of 80 piece of Nickel Titanium and Elgilloy wires; Each wire divided into four groups (10 wires for each group: control. one, two and four weeks of emersion in artificial saliva). The specimens were tested with tensile procedure and plotted the load stress- strain curve, form this curve can calculate the elasticity modulus, elasticity limit and plasticity limit. The results were subjected to the descriptive statistics, ANOVA and Duncan's Multiple range analyses at $p \leq 0.05$ significant level. Results: The Results demonstrated that the modulus of elasticity, elasticity limit and plasticity limit of the Nickel Titanium and Elgilloy arch wires decrease significantly as the emersion time in the artificial saliva increase. Conclusions: The decrease of the biomechanical properties (modulus of elasticity, elasticity limit and plasticity limit) of the Nickel Titanium Elgilloy arch wires which subjected to the artificial saliva did not encourage the using of these arch wires clinically for long time. Key words : Modulus of elasticity, elasticity limit, plasticity.
\end{abstract}

Obaidi HA, Al-Qassar SS. Elasticity and Plasticity Behaviors of the Orthodontic Arch Wires. AlRafidain Dent J. 2011; 11(1):6-11.

Received: 4/3/2009 Sent to Referees: 4/3/2009

Accepted for Publication: 22/4/2009

\section{INTRODUCTION}

Fundamental mechanical properties of metals are related to the amounts of deformation which metals can withstand under different circumstances of force application. ${ }^{1}$ The archwire should behave elastically over a period of weeks to months. ${ }^{2}$ Elastic modulus is the measure of the stiffness of a material and high numbers are unusual for this property. ${ }^{3}$ Klump et $a l^{4}$ stated that as the modulus of elasticity value increases, the wire stiffness increases too. The slope of the straight-line por- tion of the stress -strain curve gives a measure of the modulus of elasticity. ${ }^{5}$

The maximum deformation that a body (e.g. wire or appliance part) can undergo before the permanent (plastic) deformation occurs. ${ }^{6}$ The resilience is the capacity of the material to absorb energy when its deformed elastically. ${ }^{7}$ Ductility indicates the amount of plastic deformation or strain that can occur before the material fracture. ${ }^{8}$

The aims of this study are planned to evaluate and compare the mean values of the elasticity and plasticity of the Elgyloy 
and Nitinol arch wires which are immersed in artificial saliva for one, two and four weeks.

\section{MATERIALS AND METHODS}

The samples comprised of 80 piece wires ( 40 piece of wires for each of Nickel Titanium and Elgilloy wires. Nickel Titanium wire $\left(0.016^{\prime \prime} \times 0.016^{\prime \prime}\right.$ Rocky Mountain Orthodontics, U.S.A) and Elgilloy wire (Remanium 0.016" $\times 0.016^{\prime \prime}$ Dentarum, Germany) . each type of wires divided into four groups (10 wires of each), The first ,second ,third and fourth groups of the both arch wires were tested at the following conditions: non treated wire (control group),one, two, and four weeks immersion in artificial saliva $(\mathrm{PH}$ $6.75 \pm 0.015)^{9}$ with incubation at 37 degree centigrade (Incubator; Isotemp; Germany) the most revenant mouth temperature.

Tensile is one of the most useful mechanical tests because of the data that can be obtained from it represent the mechanical properties which describe the behavior of the material subjected to the mechanical force. $^{\mathbf{1 0}}$ It is recommended in American Dental Association (ADA) specification. ${ }^{11}$ All the specimens were tested with tensile testing machine (Zweigle model 73, Belgique). The speed of the machine adjusted as $0.5 \mathrm{~mm} / \mathrm{sec}$. There is a special ruler build in the machine for detecting the change in the length of the specimen until rupture. the tensile stress transferred from $\mathrm{Kg}$ to $\mathrm{N}$ by $\mathrm{N}=\mathrm{Kg} \times 10$. and then to Mpa by stress $=($ load in $\mathrm{N}) /($ surface area of the specimen $2 \mathrm{~mm}^{2}$ ). Plotting the load stress - strain curve (Figure 1) from this curve most the mechanical properties can be obtained such as the point at which fracture occurs represents failure stress, the elastic limit (represents the area between zero stress and the yield stress), the plastic limit (represents the area between yield and failure stress) and the modulus of elasticity (which represents $\tan \varnothing$ $=$ stress/strain). ${ }^{10}$ The results analyzed by using the Descriptive and (ANOVA and Duncan's Multiple range analyses at $p \leq$ 0.05 significant level).

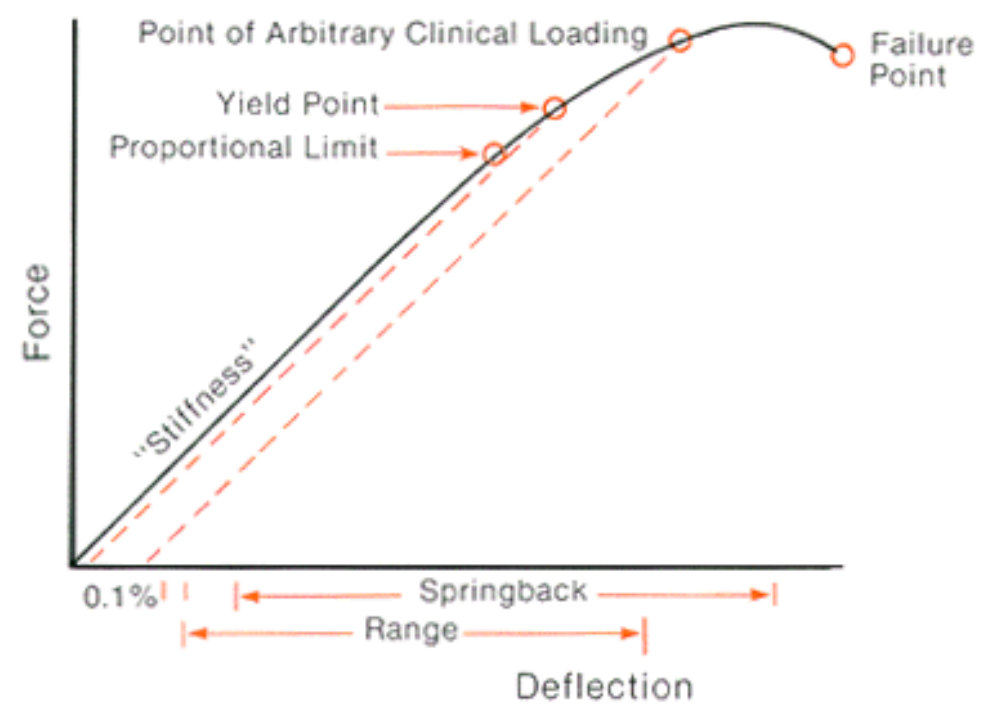

Figure (1): The curve to calculate the modulus of elasticity, elastic limit and plastic limit . Staggers and Margeson ${ }^{10}$ Asgharnia and Brantley ${ }^{11}$.

\section{RESULTS}

The descriptive statistics, ANOVA and Duncan's Multiple range analyses the of modulus elasticity, elastic and plastic limits (mechanical properties) of the Niti- nol and Elgilloy arch wires disclosed in (Tables 1, 2, 3 and 4). Both the wires displayed a decrease significantly in their mechanical properties as increasing the arch wire immersion time. 
Table (1): The Descriptive analyses and Anova test of the Nitinol wire.

\begin{tabular}{|c|c|c|c|c|c|c|c|c|}
\hline Property & Groups & $\mathbf{N}$ & Mean & \pm SD & $\begin{array}{c}\text { Min } \\
\text { value }\end{array}$ & $\begin{array}{l}\text { Max } \\
\text { value }\end{array}$ & $\begin{array}{c}\text { Anova } \\
\text { F-value }\end{array}$ & Sig \\
\hline \multirow{4}{*}{$\begin{array}{l}\text { Modulus of elasticity } \\
\text { (MPa) } \times 10^{3}\end{array}$} & Control group & 10 & 123.50 & 2.677 & 118 & 127 & \multirow{4}{*}{118.17} & \multirow{4}{*}{$\mathrm{S}$} \\
\hline & 1 week after & 10 & 120.20 & 2.098 & 115 & 127 & & \\
\hline & 2 weeks after & 10 & 116.10 & 2.558 & 105 & 125 & & \\
\hline & 4 weeks after & 10 & 109.40 & 3.273 & 98 & 120 & & \\
\hline \multirow{4}{*}{$\begin{array}{l}\text { Elastic limit } \\
\text { (Mpa) } \mathbf{x 1 0}^{3}\end{array}$} & Control group & 10 & 531.90 & 1.792 & 530 & 535 & \multirow{4}{*}{4173.472} & \multirow{4}{*}{ S } \\
\hline & 1 week after & 10 & 506.90 & 1.449 & 505 & 510 & & \\
\hline & 2 weeks after & 10 & 486.40 & 1.647 & 480 & 490 & & \\
\hline & 4 weeks after & 10 & 470.20 & 1.687 & 451 & 480 & & \\
\hline \multirow{4}{*}{$\begin{array}{l}\text { Plastic limit } \\
\text { (Mpa) } \times 10^{3}\end{array}$} & Control group & 10 & 1266.00 & 2.000 & 1263 & 1269 & \multirow{4}{*}{2946.999} & \multirow{4}{*}{$\mathrm{S}$} \\
\hline & 1 week after & 10 & 1236.20 & 2.251 & 1215 & 1250 & & \\
\hline & 2 weeks after & 10 & 1217.90 & 10.148 & 1107 & 1241 & & \\
\hline & 4 weeks after & 10 & 1169.70 & 2.163 & 1062 & 1268 & & \\
\hline
\end{tabular}

S: Significant difference $(p=0.001)$.

Table (2): Duncan`s multiple analysis range test for the NiTi wire.

\begin{tabular}{|c|c|c|c|c|}
\hline Property & Groups & $\mathbf{N}$ & Mean & Duncan group* \\
\hline \multirow{4}{*}{$\begin{array}{l}\text { Modulus of elasticity } \\
\text { (MPa) } \mathbf{x 1 0}^{3}\end{array}$} & Control group & 10 & 123.50 & $\mathrm{D}$ \\
\hline & 1 week after & 10 & 120.20 & $\mathrm{C}$ \\
\hline & 2 weeks after & 10 & 116.10 & $\mathrm{~B}$ \\
\hline & 4 weeks after & 10 & 109.40 & $\mathrm{~A}$ \\
\hline \multirow{4}{*}{$\begin{array}{l}\text { Elastic limit } \\
\text { (Mpa) x10 }\end{array}$} & Control group & 10 & 531.90 & $\mathrm{D}$ \\
\hline & 1 week after & 10 & 506.90 & $\mathrm{C}$ \\
\hline & 2 weeks after & 10 & 486.40 & $\mathrm{~B}$ \\
\hline & 4 weeks after & 10 & 470.20 & $\mathrm{~A}$ \\
\hline \multirow{4}{*}{$\begin{array}{l}\text { Plastic limit } \\
\text { (Mpa) } \times 10^{3}\end{array}$} & Control group & 10 & 1266.00 & $\mathrm{D}$ \\
\hline & 1 week after & 10 & 1236.20 & $\mathrm{C}$ \\
\hline & 2 weeks after & 10 & 1217.90 & B \\
\hline & 4 weeks after & 10 & 1169.70 & $\mathrm{~A}$ \\
\hline
\end{tabular}

* Different letters mean significant difference at $p \leq 0.05$.

Table (3): The Descriptive analyses and Anova test of the Elgilloy wire

\begin{tabular}{|c|c|c|c|c|c|c|c|c|}
\hline Property & Groups & $\mathbf{N}$ & Mean & \pm SD & $\begin{array}{c}\text { Min } \\
\text { value }\end{array}$ & $\begin{array}{l}\text { Max } \\
\text { value }\end{array}$ & $\begin{array}{c}\text { ANOVA } \\
\text { F-value }\end{array}$ & Sig \\
\hline \multirow{4}{*}{$\begin{array}{l}\text { Modulus of } \\
\text { elasticity } \\
(\mathrm{MPa}) \times 10^{3}\end{array}$} & Control group & 10 & 207.60 & 2.757 & 205 & 212 & \multirow{4}{*}{55.163} & \multirow{4}{*}{$\mathrm{S}$} \\
\hline & 1 week after & 10 & 204.60 & 2.875 & 200 & 210 & & \\
\hline & 2 weeks after & 10 & 200.80 & 2.616 & 198 & 205 & & \\
\hline & 4 weeks after & 10 & 193.00 & 2.000 & 190 & 195 & & \\
\hline \multirow{4}{*}{$\begin{array}{l}\text { Elastic limit } \\
\text { (Mpa) } \times 10^{3}\end{array}$} & Control group & 10 & 766.10 & 1.595 & 765 & 770 & \multirow{4}{*}{67.335} & \multirow{4}{*}{$\mathrm{S}$} \\
\hline & 1 week after & 10 & 741.60 & 3.565 & 735 & 755 & & \\
\hline & 2 weeks after & 10 & 717.80 & 32.286 & 672 & 777 & & \\
\hline & 4 weeks after & 10 & 694.20 & 34.714 & 534 & 750 & & \\
\hline \multirow{4}{*}{$\begin{array}{l}\text { Plastic limit } \\
\left(\text { Mpa) } \times 10^{3}\right.\end{array}$} & Control group & 10 & 1623.70 & 1.767 & 1620 & 1626 & \multirow{4}{*}{.782} & \multirow{4}{*}{$\mathrm{S}$} \\
\hline & 1 week after & 10 & 1591.20 & 1.317 & 1560 & 1634 & & \\
\hline & 2 weeks after & 10 & 1563.20 & 1.814 & 1490 & 1596 & & \\
\hline & 4 weeks after & 10 & 1513.60 & 39.84 & 1405 & 1541 & & \\
\hline
\end{tabular}

S: significant difference $(p=0.001)$. 
Table (4): Duncan`s multiple analysis range test for the Elgilloy wire.

\begin{tabular}{|c|c|c|c|c|}
\hline Property & Groups & $\mathbf{N}$ & Mean & Duncan agroup* \\
\hline \multirow{4}{*}{$\begin{array}{l}\text { Modulus of elasticity } \\
\text { (MPa) } \times 10^{3}\end{array}$} & Control group & 10 & 207.60 & D \\
\hline & 1 week after & 10 & 204.60 & $\mathrm{C}$ \\
\hline & 2 weeks after & 10 & 200.80 & B \\
\hline & 4 weeks after & 10 & 193.00 & A \\
\hline \multirow{4}{*}{$\begin{array}{l}\text { Elastic limit } \\
\text { (Mpa) } \times 10^{3}\end{array}$} & Control group & 10 & 766.10 & D \\
\hline & 1 week after & 10 & 741.60 & $\mathrm{C}$ \\
\hline & 2 weeks after & 10 & 717.80 & B \\
\hline & 4 weeks after & 10 & 694.20 & A \\
\hline \multirow{4}{*}{$\begin{array}{l}\text { Plastic limit } \\
\text { (Mpa) } \times 10^{3}\end{array}$} & Control group & 10 & 1623.70 & $\mathrm{D}$ \\
\hline & 1 week after & 10 & 1591.20 & $\mathrm{C}$ \\
\hline & 2 weeks after & 10 & 1563.20 & B \\
\hline & 4 weeks after & 10 & 1513.60 & A \\
\hline
\end{tabular}

* Different letters mean significant difference at $p \leq 0.05$.

\section{DISCUSSION}

The significant decrease of all mechanical properties in all intervals in comparison with control group for the Nickel titanium (NiTi) and Elgilloy (Elg) arch wires, could be due to the effect of saliva on arch wire which coats the arch wire with proteniaceous integument. The proteniaceous integument masks the alloy surfaces to an extent that it could depend on the immersion time. ${ }^{12}$ The arch wire properties affected in 7 days. ${ }^{13}$ The saliva potentially corrodes alloys and the maximum ion release always occurs in $1 \mathrm{st}$ day. ${ }^{14}$ The decrease in the fourth group is more significant than the second and the third; and the decrease in the third group is also significant than the second group; this indicates that the properties decrease by increase of the immersion period; and this conforms with that of authors. ${ }^{15,16}$

For the modulus of elasticity, elastic limit properties of the NiTi arch wire; the significant decrease of these properties in all intervals compared with control group is due to the corrosion effect of saliva ${ }^{14}$, and arch wire properties are affected in 7 days. ${ }^{13}$ Pitting and crevices corrosion occur on the surface of the arch wire, ${ }^{12}$ and due to the effect of electrolyte media, ${ }^{17}$ this agrees with Kapila et al. ${ }^{18}$ who suggested that the use of arch wire may be associated with a decrease in the elasticity of arch wire. The researchers $^{14,19}$ stated that NiTi arch wire should be removed after 4 weeks; however; disagrees with Buckthal and Kusy. ${ }^{20}$ For the plastic limit; the NiTi arch wire gives rise to a significant decrease in the amount of change of mechanical property; this could be due to high stability of the titanium oxide on the surface of the arch wire as stated by Zavanilli et al $^{21}$ that maximizes the corrosion resistance of the alloy in addition to that titanium has the ability to resynthesis of the passivation film and this agrees with Canay et $a l^{22}$ who reported that repassivation will be observed on the NiTi arch wire in artificial saliva. The plastic limit properties intra oral exposure of the arch wire causes embrittlement of hydrogen ion in the saliva and leads to degradation of the mechanical properties due to stress crack corrosion of the arch wire. ${ }^{19}$ The results are in accordance with that of Tang et al. ${ }^{13}$ and in contrast to that of Smith et al. ${ }^{23}$

The significant decrease in all mechanical properties of the Elgiloy arch wire in all intervals when compared with the control group; could be due to that the arch wire properties are affected by immersion in artificial saliva 
which is due to the effect of the corrosion on the surface of the arch wire. ${ }^{24}$ The modulus of elasticity and elasticity limits of the Elgilloy arch wire are affected by the immersion in the saliva the results are in accordance with that of Tang et al. ${ }^{13}$ and in contrast with that of Smith et al. ${ }^{23}$ (1992) who reported that the Elgilloy wire do not significantly affected by the immersion in saliva. The plastic limit properties intra oral exposure of the arch wire causes embrittlement of hydrogen ion in the saliva and leads to degradation of the mechanical properties due to stress crack corrosion of the arch wire. ${ }^{19}$ The results are in accordanced with that of Tang et al. ${ }^{13}$ and in contrast to that of Smith et al. ${ }^{23}$

\section{CONCLUSIONS}

The conclusions of this study are that the elasticity and plasticity of the Nickel Titanium and Elgilloy arch wires are decrease significantly when increasing the immersion time. It is recommended to not elongate the time of using these arch wires in the clinical treatment.

\section{REFERENCES}

1. Hibbeler H. Mechanics of material. $5^{\text {th }}$ ed. Hodder and Stoughton publisher. 2003; Chapter 2; P: 92.

2. Kusy RP. A review of contemporary archwire: Their properties and characteristic. Angle Orthod.1977; 3(2): 197-207.

3. Craig R, Obrien W, Powers J. Dental material properties and manipulation. $6^{\text {th }}$ ed, Mosby publisher.1996; Pp: 1927.

4. Klump M, Duncanson N, Nanda T, Currier C. Elastic energy/stiffness ratios for wires. Am J Orthod Dentofacial Orthop. 1994; 96(6):588-596.

5. Proffit WR, Fields HW, Ackerman JL. Contemporary orthodontic. $3^{\text {rd }}$ ed. ST. Louis, Mosby Years book publisher. 2000; Pp: 326-340.
6. Daskalogiannakis J. Glossary of orthodontic terms. Quintessence publishes Co. Inc. 2000; Pp: 36, 92, 103, 173, 181, 182, 204, 220, 225, 226, 280.

7. Callister JR. Fundamental of materials science and enginnering. $1^{\text {st }}$ ed. John Wiley and Sons Int. 2001; p: 167.

8. Riley WF, Sturges LD, Morris DH. Static and mechanics of materials an integrated approach. $2^{\text {nd }}$ ed. John Wright and Sons Ltd. 2002; Pp: 115120.

9. Barret RD, Bishara SE, Quinn JK. Biodegradation of orthodontic appliances, part 1, Biodegradation of nickel and chromium vitro. Am J. Orthod Dentofacial Orthop.1993; 103(1): 8-14.

10. Staggers JA, Margeson D. The effect of sterilization on the tensile strength of orthodontic wire. Angle Orthod. 1993; 63(2): 141-144.

11. Asgharnia MK, Brantley WA. Bending and tension tests for orthodontic wires. Am J. Orthod Dentofac Orthop.1986; 89(3): 228 - 236.

12. Eliades T, Eliades G, Athanasiou E, Brandley G. Surface characterization of retrieved NiTi orthodontic wire. Eur J Orthod. 2000; 22(4): 317-326.

13. Tang GH, Liu K, Cao HJ, lu J, Zhang $\mathrm{CW}$. Orthodontic wires in simulated oral environment: change in the mechanical properties. Shanghai Kou Qiang Yi Xue.1997; 6(3): 159-162 (Abstract).

14. Staffolani N, Damiani F, Lilli L, Guerra M, Staffolani NJ, Belcastro S, Locci P (1999) Ion release from orthodontic appliances. $J$ Dent. 1999; 27(3): 449-454.

15. Shin JS, Hwang C. In vitro surface corrosion of S.S. and NiTi orthodontic appliances. Aus Orthod J. 2003; 19(1): 13-18.

16. Kaneko K, Yokoyama K, Moriyama K, Asaoka K, Sakai J. Degradation in performance of orthodontic wires 
caused by hydrogen absorption during short-term immersion in $2.0 \%$ acidulated phosphate fluoride solution. Angle Orthod. 2004; 24(12): 487-495.

17. Yokoyama Ki, Kaneko Ka, Ogawa To, Moriyama Ke, Asaoka Ke, Sakai Ju. Hydrogen embrittlement of workhardened Ni-Ti alloy in fluoride solution. Biomaterials. 2005; 26(6): 101108.

18. Kapila S, Reichhold G, Anderson R, Watanabe L . Effect of clinical recycling on the mechanical properties of nickel-tianium alloy wires. Am J Orthod Dentofacial Orthop.1991; 100(3): 428-435.

19. Eliades T, Bourauel C. Intra oral aging of orthodontic materials: the picture we miss and its clinical relevance. Am J Orthod Dentofacial Orthop. 2005; 127(5): 403-412.

20. Buckthal JE, Kusy RP. Effects of cold disinfectants on the mechanical properties and surface topography of nickel-titanium arch wires. Am $J$. Orthod Dentofacial Orthop.1988; 94(2): 117-22.

21. Zavanelli RA, Guilherme AS, Pessanha GE, Nobelo AM, Mesquita FM. Corrosion- fatigue of laser-repaired commercially pure titanium and $\mathrm{Ti}-$ 6Al-4V alloy under different test environment. J Oral Rehabil. 2004; 31(4): 1029-1034.

22. Canay N, Hersek A, Culha A, Bilgic S. Evaluation of titanium in oral condition and its electrochemical corrosion behavior. $J$ Oral Rehabil..1998; 25(2): 759-764.

23. Smith G, Fraunhofer J, Casey R. The effect of clinical use and sterilization on selected orthodontic archwires. Am J Orthod Dentofacial Orthop. 1992; 102(6): 153-159.

24. Gursoy S, Gungor A, Sesen C. Comparison of metal release from new and recycled bracket-archwire combinations. Angle Orthod. 2004; 75(3): 92 94. 